The Wicked Problem of Social Cohesion: Moving Ahead

\begin{tabular}{|r|l|}
\hline Journal: & Journal of Social Marketing \\
\hline Manuscript ID & JSOCM-12-2018-0162.R1 \\
\hline Manuscript Type: & Empirical Paper \\
\hline Keywords: & Social cohesion, Contact theory, Participatory approach \\
\hline \multicolumn{2}{|l}{} \\
\hline
\end{tabular}

SCHOLARONE $^{\text {Im }}$

Manuscripts 


\title{
The Wicked Problem of Social Cohesion: Moving Ahead
}

\begin{abstract}
Purpose: Despite the amount of attention given to social cohesion ${ }_{2}$ divisions within many societies are becoming wider due to various factors including religious and far-right extremism and economic austerity= Given its 'wickedness', social cohesion has been researched from various dimensions. However, in order to develop an effective solutionbased programme, these multi-facets need to be brought together for a clearer way forward. This research aims to bring together multiple disciplines in order to propose a way forward in the social cohesion discourse in two ways: by developing a common conceptualisation of social cohesion and identifying an effective approach to operationalise social cohesion.
\end{abstract}

Methodology: This research adopted a critical qualitative research approach and used three expert discussion forums consisting of academics and practitioners from multiple disciplines.

Findings: The research identifies contact theory and participatory approaches as providing an effective way forward for social cohesion. Social cohesion is conceptualised in the form of factors needed to build a cohesive society as well as outcomes of a cohesive society. Using the social marketing approach of down- mid-and up_stream strategies and interventions, this research proposes a bottom-up approach to addressing the wicked problem of social cohesion.

Originality/value: Social cohesion has been discussed by various academics and practitioners from multiple disciplines. This paper developed a common conceptualisation of social cohesion based on a review of multi-disciplinary literature combined with discussions with experts from academia and practice. Relating this to the down-, up- and mid-stream social marketing, this paper also identified participatory approach, based on contact theory, as an effective way in which social marketers can achieve downstream social marketing objectives.

\section{Introduction}

Concerns about discord between people living in a community are not unheard of in almost any part of the world. These discords, often based on race, ethnicity, and religion, have always ebbed and flowed with time. Recent events around the world such as unprecedented immigration, economic crisis, and resulting austerities, as well as terror attacks have irradiated the divisions and conflicts within our societies. Recent media reports on increasing mobilisation of far-right movements across Europe (Chakelian, 2017) and America (BBC News, 2017) is only one example of the results of increasing social divisions. These increasing social divisions call for a multi-disciplinary and strategic approach to addressing issues of social cohesion.

Boarini et al. (2018) argue that we are living at a time when exclusionary values, whether they be nationalism, racism, religious conflicts or xenophobia are on the rise again and we are 
at a crossroads. The responsibility of academics, the authors claim, is to show that there are ways toward inclusion and peace. From a critical marketing perspective, Bouchet (2018) claims that marketing and its promotion of consumerism have, arguably, replaced religion and values in society. Bouchet (2018:1059) argues that marketing has focused to 'almost religiously convert citizens into consumers' at the expense of social cohesion. He calls it the 'true violence of marketing'. Psychologists seem to agree with the notion that consumerism in individuals and societies can lead to heightened negative affect and reduced social involvement (Bauer et al., 2012). The debate by psychologists, -sociologists, and critiques of marketing over the role of hedonic consumerism on social ills may continue in academia. Whichever side one may choose to take on this debate, this paper adopts the view that marketing, and especially social marketing, has a key role to play in addressing some of society's wicked problems.

Taking Rittel and Weber's (1973) conception of 'wicked problems' as being issues with no clear cause or solution, social cohesion is arguably one of the wickedest of problems with its multifaceted conceptions and implementations. The issue of social cohesion and its various aspects has been addressed by academics and practitioners from multiple disciplines including sociology, psychology, social marketing and behavioural economists to name but a few. However, it is argued here that bringing these various conceptions together would help create a more cohesive approach to addressing this wicked problem. Kennedy et al. (2017) stated that when it comes to any given wicked problem, it is difficult to agree on its definition as well as it's causes and solutions. Concurring with this view, Gurrieri et al. (2018) argued that complexities can potentially be overcome through the creation of a common language between various parties involved in any given social problem. With this in mind, this paper aims to bring together social cohesion literature and approaches from multiple disciplines in order to propose a way forward in the social cohesion discourse which is achieved through two ways. Firstly, based on literature and input from academics and practitioners working in the area of social cohesion, a common conceptualisation of social cohesion is developed. Secondly, various approaches used to achieve cohesion are reviewed with a view to identifying an effective approach which can help social marketers in planning social cohesion programmes. The inherent nature of wicked problems is such that a single solution is not always possible. Hence, what is proposed here is one way of addressing this problem. This in no way undermines or discounts other solutions but rather looks to incorporate interventions and programmes that are already taking place and highlighting the specific contributions of social marketing into the mix.

\section{Theoretical Background}

\section{Social Cohesion}

Social cohesion can be defined simply as the existence of social bonds among members of a society (Boarini et al., 2018). However, there is, unfortunately, nothing simple about social cohesion, least of all its definition. There have been multitudes of research and publications on the area of social cohesion from disciplines of sociology, psychology, social psychology and economics to name but a few (Jenson, 1998; Berger-Schmitt, 2002; Chan et al., 2006). One thing that all these disciplines agree on is that social cohesion is a multidimensional 
concept which includes social change, belonging, resilience, and integration among others (Bottoni, 2018).

One of the most regularly used approaches in the study of social cohesion is the commonality based approach (Glasford and Jonnston, 2018). The commonality based approach to social cohesion takes the view that increasing positive relations between two or more parties (often conceptualised as the majority and minority groups) is only possible through emphasising the commonalities between the groups (Gaertner and Dovidio, 2000).

Related to the commonality approach which stemmed from sociology, social psychology suggests an identity-based approach. Whereas the commonality approach promotes the emphasis of common attributes and values shared by groups within a society, the identity theory suggests the identification, creation, and promotion of a common identity among the groups. Holtug (2017) refers to this as the 'Identity Thesis' and claims that this plays a key role in contemporary politics in liberal democracies.

Both the commonality and identity-based approaches promote the idea that, in order to achieve social cohesion, we need to perhaps overcome our differences and either focus on what we share in common or create an identity that all groups can adopt as a shared identity. This is also in line with what sociologist Anderson (2006) termed 'imagined communities'. Discussing his ideas of national identities, Anderson (2006) claimed that nations are an imagined community that is both limited and sovereign. Even the smallest of communities or nations would not necessarily have knowledge of all of its members but in their minds, each member lives the image of the community or nation. They are further limited through finite and sometimes elastic boundaries that protect their sovereignty. The community is imagined based on shared symbols such as values or religions. However, rather than depicting 'Nationalism' as an ideology, it should be viewed as 'nationalism' as kinship or comradeship (Anderson, 2006).

This idea of a nation and nationally shared culture and identity has been criticised as not reflecting reality and taking a totalitarian approach. Multiple cultures within a society have often been viewed as a threat to social cohesion and the artificial, as well as unrealistic search for a unified national identity and culture, still continues (Sanjinés, 2007; Ulsaner, 2012; Keynan, 2017). In reality, it is often one culture that is imposed (dominant culture) on the 'other' which causes rejection by the 'other' of what they see as a threat to their inherent identities and sense of belonging. Boarini et al. (2018) call this the natural consequence of evolution which has helped us develop a strong disposition to bonding within our own groups (in-group) and distrust and hostility towards others (out-group). In order to preserve our identities and sense of belonging, we often withdraw from dialogue and become defensive of our cultures and build a defensive fortress within our cultural group as a protective barrier. Cultural differences are not about to disappear no matter how many generations of 'other' cultures have become established within a society. As Hall (2018: 29) argues, cultural difference is 'not a temporary, little difficulty which a dollop of goodwill on all sides will dissolve'. Furthermore, cultural boundaries are not as rigid as some might think but rather it is more porous which allows us to adapt and adopt (Braidotti, 2018).

The notion of social cohesion as being based on a shared sense of kinship and comradeship proposed by Anderson (2006) and others have also been disputed. Based on the Latin American context, Sanjinés (2007) argued that sometimes communities have harmonious 
relationships, not because of brotherhood but because they depend on each other for survival and economic success. This theory has been confirmed by researchers where, for instance, different groups within agricultural communities form bonds that are based on interdependency and mutual assistance (Lippman et al., 2018). If this is the case, then what will help promote a sense of dependency and mutual trust or in other words, a sense that each group within any given society has something worthwhile to contribute that will be of value to each other and to society at large?

Recent research has suggested that rather than focusing only on commonality, focusing on fostering respect between groups can be a more effective way to bridge the gap between communities and cultural groups (Bergsieker, et al., 2010; Glasford and Jonnston, 2018).

Respect can be either a person's own sense of acceptance within the wider society (inclusion) or the society's view of the individual or groups as being competent and capable (statusbased) (Huo and Binning, 2008). With specific reference to-minority and majority communities, Glasford and Johnston (2018) found that status-based respect was more effective in increasing the minority group's willingness to engage in collective social action.

The question then arises: if different groups within a society are to accept each other's differences (cultural, religious, etc.) and develop a sense of respect fostered by the understanding that there is inter-dependency between and within the groups, what approach or route might offer the best solution? As discussed previously, due to the 'wicked' nature of the problem, there perhaps can never be a 'best' or a single solution to creating social cohesion. However, one potential solution may be seen in the adoption of contact theory.

\section{Contact Theory \& Participatory Approach}

The origin of contact theory can be traced back to Allport (1954) who introduced the idea of contact as a way of reducing intergroup prejudices. The premise here is that when two parties start to see each other not as strangers but as humans and become familiar with one another, cultural and media stereotypes can be broken down. This can, in turn, result in communities living together in more harmony. Recent researches have confirmed the effectiveness of the theory. Pettigrew and Tropp (2006) conducted a meta-analysis of 515 studies and confirmed that contact between groups was a significant factor in improving attitudes. Specifically investigating ethnic prejudices, Lemmer and Wagner (2015) also confirmed the effectiveness of contact in overcoming prejudices.

Researchers have also shown that rather than any form of contact, what is more effective is sustained contact with a common goal or purpose (MacInnis and Page-Gould, 2015; Dovidio et al., 2017). For instance, groups can have indirect contact through the media. This can be done in such a way that either the negative stereotypes are challenged or reinforced. Hence, there is not always a positive outcome. Direct contact where each party has an opportunity to express, discuss and understand their diversity can, on the other hand, prove more effective in producing the desired outcomes. So it's the quality of contact that can have an impact on the effectiveness of the contact rather than simply quantity (Voci and Hewstone, 2003).

Can contact theory help foster social cohesion? In today's society with a multitude of communication channels and opportunities that is available it cannot be justified that we have a lack of understanding of various groups, cultures or religions because of indifference. 
Rather it is the refusal to communicate that is at the heart of the problem of divided societies (Bouchet, 2018). This might be a more unforgiving view and it is also possible that rather than a refusal to communicate, the problem might be that we lack opportunities for meaningful communications that are aimed specifically at exploring and understanding our differences. What contact theory provides is an understanding that, through sustained and meaningful contact, prejudices can be overcome which can lead to fostering relationships based on understanding each other which can lead to the building of trust and mutual respect. This paper suggests participatory approaches can be an effective way to provide both sustained and meaningful contact between groups.

Participatory approaches are any activity or intervention that requires the individuals to actively take part in creating and delivering the project. The premise in participatory approaches to interventions is that rather than being a passive participant, individuals and communities can take ownership of their interventions and thereby make it more meaningful and engaging for them. It is effective as it helps move people beyond what Arnstein (1969) referred to as 'degree of tokenism' (where the focus is on informing, consulting and placating the community) to 'degree of citizen power' (focus is on partnership, delegated power, and citizen/community control). Discussing dimensions of social cohesion, namely social change and social capital, Ganguly (2017) claims that it is only through active and meaningful participation that sustainable and strategic social change can take place. Within the context of his work in the theatre, Ganguly (2017) builds on the work of Boal (1979) and terms this 'spectactivism' whereby an individual takes part in a performance that makes them rethink concepts under consideration and is moved from being a spectator and actor into being a 'spectactivist'. These participatory approaches are not necessarily aimed at solving a social problem or an issue. Rather it's a platform providing people with an intellectual journey to learn and evolve through participation and reconstruct their understanding of the social issue in question (Ganguly, 2017).

Participatory approaches to understand and promote social issues are well accepted in sociology (e.g. Myers, 2010; Heddon and Turner, 2012) and its potentials are only now being harnessed by social marketers (South et al., 2017). The concept of participation in social marketing is linked to the commercial marketing concept of value co-creation (Desai, 2009). Domegan et al. (2013) explain that value creation in social marketing rests upon people becoming direct and active participants in social change processes. This participation can take various forms including co-production, collaboration, facilitation and co-learning. Extending this idea into community-based social marketing, South et al. (2017) reviewed research within the health sector to identify four main roles of participatory approaches: strengthening communities, volunteer and peer roles, collaborations and partnerships, and access to community resources. It is generally agreed by many social marketers that active participation and engagement of stakeholders, including the target audience, is key when trying to tackle wicked problems (e.g. McKenzie-Mohr, 2000; French and Gordon, 2015; Kennedy, et al., 2017; Gurrieri et al., 2018; Wood, 2019). Not only does this ensure that the problem is being addressed with the participant and community needs at the forefront but it also helps eliminate concerns of ethics within social marketing. Any attempt to change society may be perceived as being manipulative (Pang and Kubacki, 2015) and giving the audience the opportunity to become active participants can provide transparency and 
inclusivity which can help overcome the sense of manipulation (Domegan et al., 2013; Pang and Kubacki, 2015). Participatory approaches provide a wide range of intervention tools for social marketers ranging from drama, art, music, and sports to name but a few. Yassim (2013) provided a discourse on the use of sport in connecting communities in which it was argued that participatory approaches, such as sports, provides a common platform where individuals from various backgrounds can come together to explore and reconcile their differences. This is also in agreement with the concept of shared beliefs where identifying shared beliefs that different parts of the community hold about a given issue can help bring people together to address a social problem (Calderon, 2019).

\section{Methodology}

The purpose of this research is to bring together multiple disciplines in order to propose a way forward in the social cohesion discourse in two ways: by developing a common conceptualisation of social cohesion and identifying an effective approach to operationalise social cohesion. In order to achieve this, a critical qualitative methodology was used to engage those who are interested in social cohesion in a discourse. These include academics for various disciplines of sociology, psychology and behavioural economics as well as practitioners engaged in social cohesion projects.

Critical qualitative methodologies are approaches that go beyond the 'interpretation' of a phenomenon to a more engaged discourse with a view to providing solutions to social issues (Denzin et al., 2017). This approach can help understand how to define a complex social construct and how the agenda should be moved forward with the input of those who are involved in the area under discussion (Denzin, 2017).

For this research, three discussion forums were held over a period of one year in the United Kingdom. The events were advertised via the author institute marketing channels for internal and external participants. Overall, thirty participants took part in the discussion with approximately ten in each session. The participants came from a multidisciplinary background and included academics (12 including marketing, sociology, economics and psychology) and practitioners involved in working within areas of community development (18 working in areas such as radicalisation, youth violence, youth empowerment, migrant and cultural integration). Participants engaged in discussions around the following areas: conceptualising social cohesion; the need for further work on social cohesion; the target groups for any social cohesion interventions; and relevance and appropriateness of participatory approaches in social cohesion._The discussions from the forums were thematically analysed and set within the context of existing research and approaches of social cohesion as discussed below.

\section{Discussion on Findings}

The findings from the thematic analysis of the discussion forums are threefold. Firstly, as called for by various social marketing literature on addressing complex and wicked problems (e.g. Kennedy et al., 2017; Gurrieri et al., 2018), a common conceptualisation of social cohesions with its various dimensions and its potential impacts was identified. Secondly, it 


\section{Social Cohesion - Developing a Conceptualisation}

It should be noted here that at the conception of this research, the project was termed as 'community cohesion'. Before the concept of community cohesion could be defined, the participants felt that the terminologies need to be addressed. As one participant from the first discussion forum questioned:

'what exactly are we talking about here? Community cohesion or social cohesion?' (practitioner 1.1, youth empowerment)

This was in line with the multiple terminologies used in literature which ranged from neighbourhood, community, and society when discussing cohesion (Thomas et al., 2018). Although there was a difference in scope when using these different terminologies, participants here felt that they are often used interchangeably. Cohesion can happen at different levels: within a local neighbourhood consisting of one or two streets (Erdem et al., 2016), a community that consists of a town or locality or a homogenised group living within a locality (Thomas et al., 2018); national or regional level (Bottoni, 2018). The participants felt that all of these levels may need to be addressed (this will be discussed in more detail below and outlined in Figure 2) but the project should be addressed as social cohesion. The term 'social' can be interpreted as being within a nation, region or community. However, the participants felt that this is a more overarching level of cohesion that is the ultimate aim of the project as demonstrated below:

.... whether it starts from neighbourhoods or cities, ultimately what we are trying to achieve is a cohesive society.' (academic 1.4, sociology)

As such, the project was henceforth referred to as 'social cohesion'. It should be noted that this is also in line with how the British Academy's recent Green Paper views the concept (British Academy, 2018).

Moving on from this, participants discussed what social cohesion is with a view to developing a conceptualisation. As stated before, the simplest of definitions is the idea of social cohesion as the existence of social bonds within members of a society (Boarini et al., 2018). There are also definitions of social marketing that incorporates some of the complexities of the concept such as 'a cohesive society is characterised by social relationships, a positive emotional connectedness between its members and the community, and a pronounced focus on the common good' (Bertelsmann-Foundation, 2013: 11). It was clear during the discussion that when participants were expressing what social cohesion means to them, they were using the various causes and also outcomes of social cohesion. For instance: 
Some of the causes of social cohesion were outlined before including: understanding and acknowledging diversity; trust between various groups within society; respect for each other at the individual and group level, instilling a sense of belonging; social justice involving equality and equity of treatment in legislative environments; and economic justice involving distribution of income, access to education and opportunities and employment (e.g. Sanjinés, 2007; Erdem et al., 2016; Holtug, 2017; Le Roux et al., 2018; Abdullah et al., 2018; Glasford and Jonnston, 2018; Boarini et al., 2018). The outputs of social cohesion that were discussed by the participants were also in line with the literature. Numerous researches have shown that social cohesion has a positive impact on people's mental as well as physical health (e.g. Delhey and Dragolov, 2016; South et al., 2017; Lippman et al., 2018). This is because a connected and cohesive society makes diffusion of health information more effective as well as providing a more effective support network for vulnerable individuals. Resilience is defined as the capacity to bounce back quickly from life-changing or stressful events (Smith et al., 2008). Authors have made the distinction between the resilience of an individual and resilience of the community (Lyons et al., 2016). The current research considers resilience as an outcome of social cohesion and hence social resilience is primarily the focus here. However, participants argued that individual and social resilience can both occur concurrently as a result of social cohesion so this would need to be explored further in future research. Nevertheless what is evidenced is the relationship between resilience and social cohesion (e.g. Patel and Gleason, 2018). Social capital is often defined as a feature of societies to be able to facilitate coordinated actions with the aim of social and economic benefits (Putnam et al., 1994). Further, some researchers have pointed out that whereas social cohesion is about 'being' or a state, social capital is about 'having' (Carrasco and Bilal, 2016). The participants concurred with this as they felt that you need to be a cohesive society in order to harness the power of that society to create social change through the utilisation of its social capital.

\section{'to me, social cohesion is about people working together for a better society.' (practitioner, 2.1, migrants integration)}

Finally, the link between social cohesion and potential impact on radicalisation was discussed by the participants. Although no research to-date has evidenced a direct link between social cohesion and radicalisation, Yassim (2013) argued that a cohesive society can minimise the risk of radicalisation among young people. A Home Affairs Select Committee report in the UK (2012) identified that lack of representation in the social and political processes and a sense of exclusion were major drivers of radicalisation. Derived from these discussions and the literature, Figure 1 illustrates the conceptualisation of the social cohesion developed here and proposed as a working conception of social cohesion. 


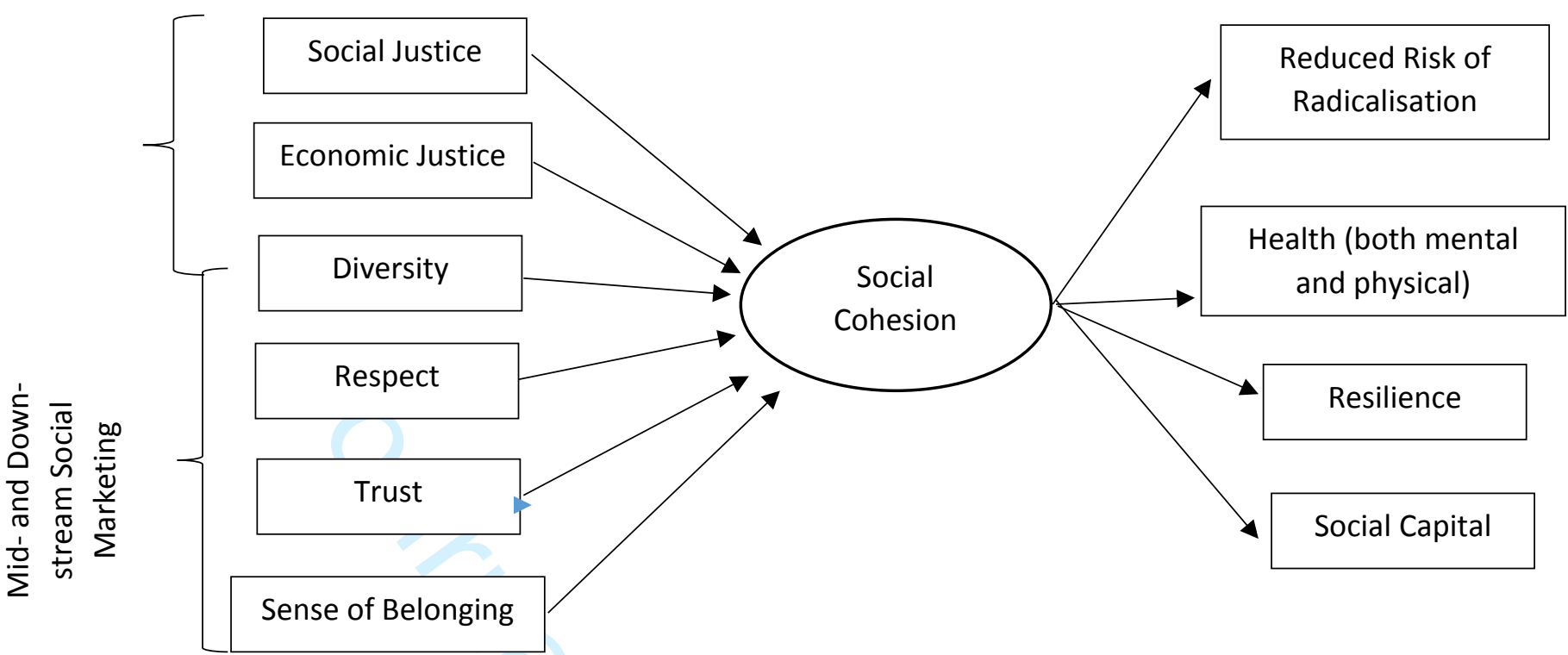

Figure 1: Proposed Concpetualisation of Social Cohesion

\section{Levels of Social Cohesion and the Target Audience}

During the first discussion forum, the participants were sharing and discussing examples of cases that they have come across involving individual youth and their attitudes and lack of a sense of belonging within their communities. This discussion was held in the context of social cohesion or lack thereof within certain parts of the community. At one point in the discussion, one of the participants mentioned that he was feeling confused.

\section{'sorry, I thought we were discussing social cohesion. Individuals don't make a society so how do the two link?' (academic 1.2, economics)}

This paved the way to the discussion of target groups and audiences for a social cohesion intervention and was explored further in each of the subsequent focus groups. Analysis of these discussions identified the various levels or groups that needed to be targeted in addressing social cohesion as well as how this links with the well know social marketing concept of down-, mid- and up-stream as shown in Figure 2.

Delhey and Dragolov (2016) claim that the concept of cohesion in sociology and social psychology always signifies a collective dimension. The authors further argue that cohesion cannot be understood or studied as an 'individual' concept as an individual cannot denote cohesion on their own. However, others have argued that, although social cohesion is a collective term, individuals who make up that society have a key role to play. Lippman et al. (2018) for example argued that as well as group cohesion, an individual's perceived cohesion of the group or society is also an important factor in facilitating group cohesion. The authors found that there can be dissonance between social cohesion on an individual level (perceived cohesion) and cohesion at the group or society level (actual cohesion). Additionally, Bottoni (2018) argued that methodological individualism is an important part of operationalising 
social cohesion. They claim that positive ties and the interaction among individuals are a foundation for a society to build its cohesion upon. In other words, interpersonal trust needs to be in place first before we can expect social groups or communities to trust each other at an aggregate level. Participants agreed that dealing with trust, respect, and sense of belonging at an individual level is important if we are to ever achieve these at a societal level:

\section{'yes an individual doesn't make a society but there is also no society without the individuals.' (academic 2.2, sociology)}

The individuals are the roots or foundations of the society and their attitudes (strength of the foundation) will manifest in inter-group and inter-community relationships. Taking this on board as well as Whelan and Maitre's (2005) suggestion of analysing social cohesion at the levels of micro (relations among individuals), meso (relationships among individuals and groups) and macro (relationships among individuals and society), this research found that building social cohesion needs to take a scaffolded bottom-up approach as shown in Figure 2.

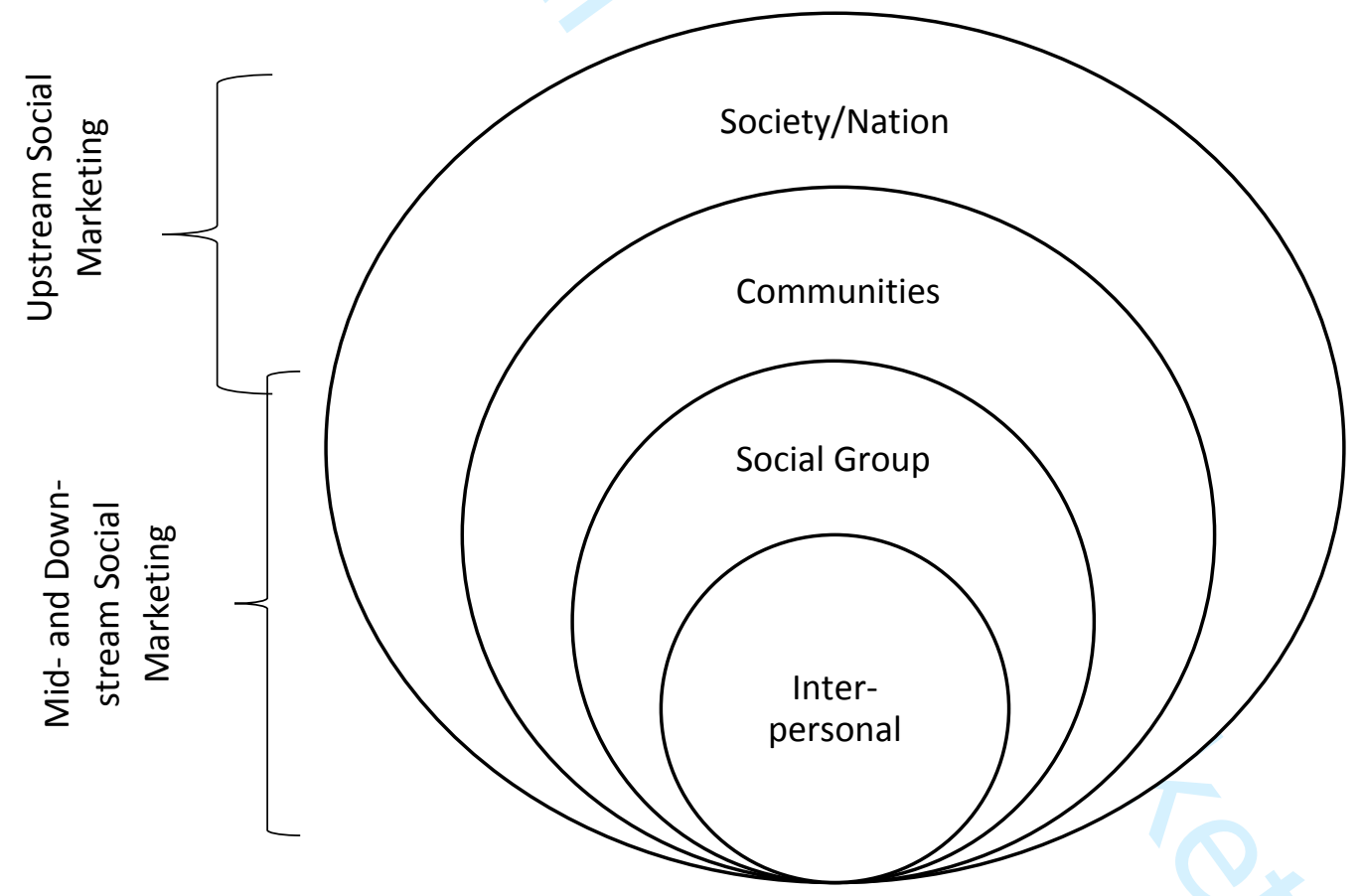

Figure 2: Bottom-up Approach of Interventions for Social Cohesion

The bottom-up approach to social cohesion is a clear indication also of the contribution of social marketing towards this concept as expressed by a participant:

'often social interventions don't do an in-depth analysis of the various audience which marketing does as standard when developing campaigns. I mean, that's the main premise of segmentation and targeting..' (academic 1.1, social marketing)

As with the conception of social cohesion shown in Figure 1, the bottom-up approach also shows that interventions to achieve the desired outcomes (e.g. respect, trust, sense of belonging), the idea of midstream, downstream and upstream social marketing provides an effective solution. Upstream social marketing which aims at creating policy changes and 


\section{Participatory Approaches - The Verdict}

This research found that participatory approaches based on contact theory can be an effective intervention in addressing social cohesion at down- to mid-stream level. The practitioners present at the discussion forums as well as sociologists were familiar with the concept of participatory approaches. Using participatory approaches in various aspects of social issues such as integration, rehabilitation and empowerment are not novel concepts. As mentioned previously, initiatives such as the Theatre of the Oppressed (Boal, 1979) has been present for decades. More recent examples identified by participants include: The Change Foundation = sport-based to address issues including refugee integration, youth offender rehabilitation, and youth empowerment; London based 3 Faiths Forum - a theatre group to bring together individuals from Christian, Jewish and Islamic faiths; Musicians Without Borders - musicbased work on refugee integration and giving a voice to marginalised groups.

In reviewing and discussing various participatory approaches, it was identified that arts and music based participatory approaches are likely to be more effective in this context. The rationale for this was that creative projects are a powerful tool for expressing and sharing diverse opinions and developing more cohesive communications with multiple audiences (Berman, 2017). As Lederach (2005) claimed creativity has the potential to open people to avenues of inquiry and provides a new way to conceptualise and deal with social change. It was clear then that participatory approaches in general and arts and music based approaches, 
in particular, are seen as being effective and already exists. The question then becomes, if these projects already exist, why then have we not seen any visible impact of them in our society?

It was felt that often these projects exist in silos and are not designed nor equipped to widen the impact in meaningful ways. In addition, these participatory projects can often be a forum for sharing ideas and opinions with little emphasis on tangible outcomes.

'there are obviously many smaller-scale projects that happen in and around London but we need to have a strategic approach to create wider impact.' (practitioner 3.2, de-radicalisation)

It was previously mentioned that work such as the Theatre of the Oppressed are not necessarily aimed at solving a social problem or an issue but rather a platform for people to learn and evolve through participation and reconstruct their understanding of the social issue in question (Ganguly, 2017). This research found that, in order to achieve a wider impact, participatory approaches need to focus more on achieving outcomes that go beyond mere engagement. Social marketing can contribute here through its focus on behaviour change which will bring a more outcome driven approach to these projects through the following: using down-, mid- and up-stream social marketing to effectively target audiences and develop communications; starting from a bottom-up/down-stream level, build movements within communities to scale-up and widen impact of the interventions; develop specific behaviour change outcomes for the interventions in order to enable effective evaluation of impact-

This research does not detract from the work and efforts of all organisations involved in using participatory approaches to create social change. What is argued here is that a more cohesive and strategic approach towards these initiatives are needed if we are to see wider and sustained impact. By its inherent nature of involving individuals, the participatory approaches deal with down_-and mid_stream level change. In order to achieve the bottom-up change proposed in this research, participatory research provides an effective starting point which combined with creating social movements discussed in social marketing (e.g. Gurrieri et al., 2018) can help scale up the interventions to a wider audience.

\section{Conclusion}

We are living in a society today where divisions between parts of societies are becoming wider due to various life events including the economic crisis and austerity, unprecedented migration, and refugee crisis, rising far-right and religious and ideological extremism. The need for measures and initiatives to foster a cohesive society has perhaps never been more apparent. Social cohesion and its various facets have been studied and discussed over many decades. Yet, we fail to see much wider society level impacts in most parts of the world. In line with literature on wicked problems calling for a common language as a first step towards addressing complex issues, this research aimed to bring people from multi-disciplines and backgrounds to discuss and identify a way to move this agenda forward in a meaningful way. This was achieved in two ways.

Firstly, this paper developed a common conceptualisation of social cohesion which brought together the various dimensions and the potential outcomes of social cohesion. This provides 
a common language for working in social cohesion and related areas to understand the scope of the concept and what is involved in developing social cohesion. Furthermore, this also provides social marketers insight into which dimensions of social cohesion can be addressed by using strategies of down-, mid- and up-stream social marketing. This research suggests that down- and mid-stream social marketing strategies are needed to develop respect, sense of belonging, and trust. On the other hand, developing diversity, social and economic justice requires up-stream social marketing strategies. The findings from this research also identified the different levels of audiences that need to be addressed when dealing with social cohesion which is in line with the systems approach of addressing wicked problems proposed by social marketers (e.g. Wood, 2019). The findings here suggest that, even though social cohesion needs to be addressed using a combination of down-, mid- and up-stream social marketing, a bottom-up approach which begins with the individuals and smaller communities would be an effective starting point.

Secondly, in order to start operationalising social cohesion based on a bottom-up approach, this research identified contact theory-based participatory approach as being an effective tool. Arts and music based participatory approaches, in particular, provide a rich environment where people can come together to express views, share ideas and foster, trust, respect and sense of belonging within their communities. As the participants in this research agreed, these provide a safe space for people to discuss issues and express opinions they may not be able to openly do elsewhere. With the contribution of social marketing through its focus on behaviour change and ability to effectively segment and target audiences, these participatory approaches can be used to develop social movements within communities as a way to scaling up social cohesion interventions which can elicit wider impact as part of a cohesive bottomup approach to social cohesion.

A limitation of this research is that it is based only on a discussion of experts within the field (practitioners and academics working in areas of social cohesion) and does not consider the viewpoints of audiences and other stakeholders within the community. Future research needs to use the social cohesion conceptualisation developed here as a working conceptualisation to be refined and developed further based on research on primary target audiences and other community-based stakeholders.- Social marketers can also contribute through further research into identifying the specific behavioural outcome that these participatory approaches aim to facilitate; what is the mutual benefit that can engage audience in these interventions over a period of time; and what are some of the barriers to engaging in these interventions and behaviour change and how can these be mitigated.

It is perhaps unrealistic to expect a straightforward or simple solution for social cohesion as it is with any given wicked problem. However, as opposed to some authors' argument of social cohesion as possibly being a utopian concept (Sanjinés, 2007), this research takes the view that social cohesion is possible. It is anticipated that a multi-disciplinary and strategic approach, with the help of social marketing, has the potential to take this agenda forward with effective outcomes.

\section{References}


Abdullah, A., Marzbali, M.H., Tilaki, M.J.M. and Bahauddin, A. (2018) 'Does permeability promote social cohesion'. Asian Journal of Behavioural Studies, vol. 3, pp. 87-94.

Allport, G.W. (1954) The Nature of Prejudice. Reading, MA: Addison-Wesley.

Anderson, B. (2006) Imagined Communities. London: Verso.

Arnstein, S. (1969) 'A ladder of citizen participation'. Journal of American Planning, vol. 35, no. 4, pp. 216-224.

Bauer, M.A., Wilkie, J.E.B., Kim, J.K. and Bodenhausen, G.V. (2012) 'Cuing consumerism: situational materialism undermines personal and social well-being'. Psychological Science, vol. 23.

BBC News (2017) White Supremacy: Are US right-wing groups on the rise? Available at: http://www.bbc.co.uk/news/world-us-canada-40915356.

Berger-Schmitt, R. (2002) 'Considering social cohesion in quality of life assessments: concept and measurement'. Social indicators Research, vol. 58, pp. 403-428.

Bergsieker, H.B., Shelton, J.N. and Richeson, J.A. (2010) 'To be liked versus respected: divergent goals in interracial interactions'. Journal of Personality and Social Psychology, vol. 99, pp. 248-264.

Berman, K.S. (2017) Finding Voice: A Visual Arts Approach to Engaging Social Change. San Francisco: University of Michigan Press.

Bertelsmann-Foundation (2013) Social Cohesion Radar - Measuring Common Ground: An International Comparison of Social Cohesion. Gutersloh:Germany: Bertelsmann-Foundation.

Boal, A. (1979) Theatre of the Oppressed. London: Pluto Press.

Boarini, R., Causa, O., Fleurbaey, M., Grimalda, G. and Woolard, I. (2018) 'Reducing inequalities and strengthening social cohesion through inclusive growth: A roadmap for action'. Economics: The Open-Access, Open-Assessment E-Journal, vol. 12, pp. 1-26.

Bottoni, G. (2018) 'A multilevel measurement model of social cohesion'. Social Indicators Research, vol. 136, pp. 835-857.

Bouchet, D. (2018) 'Marketing, violence and social cohesion: first steps to a concpetual approach to the understanding of of the normalising role of marketing'. Journal of Marketing Management, vol. 34, pp. 1048-1062.

Braidotti, R. (2018) 'Becoming-World: A New Perspective on European Citizenship.' in Lafleur, B., Maas, W. and Mors, S. (eds.) Courageous Citizens: How Culture Contributes to Social Change. Valiz: European Cultural Foundation. pp. 47-63.

British Academy (2018) Integrated Communities Strategy Green Paper: Building Stronger, More United Communities. Green Paper. British Academy.

Calderon, C. (2019) 'The importance of shared beliefs for social marketing programmes'. Journal of Social Marketing, vol. 9, pp. 26-39.

Carrasco, M.A. and Bilal, U. (2016) 'A sign of the times: to have or to be? Social capital or social cohesion?'. Social Science and Medicine, vol. 159, pp. 127-131.

Carvalho, H.C., Mazzon, J.A. and Santos, J.R. (2019) 'A tale of complexity'. Journal of Social Marketing, vol. 9, pp. 40-52. 
Chakelian, A. (2017) Rise of the Nationalists: A guide to Europe's far-right parties. Available at: https://www.newstatesman.com/world/europe/2017/03/rise-nationalists-guide-europe-s-far-rightparties.

Chan, J., To, H.P. and Chan, E. (2006) 'Reconsidering social cohesion: Developing a definition and analytical framework for empirical research'. Social Indicators Research, vol. 75, pp. 273-302.

Dawson, J. and Godec, S. (2017) Counter-extremism Policy: An Overview. Briefing Paper. House of Commons Library. Number 7238.

Delhey, J. and Dragolov, G. (2016) 'Happier together: Social cohesion and subjective well-being in Europe'. International Journal of Psychology, vol. 51, pp. 163-176.

Denzin, N.K. (2017) 'Critical qualitative inquiry'. Qualitative Inquiry, vol. 23, pp. 8-16.

Denzin, N.K., Lincoln, Y.S., MacLure, M., Otterstad, A.M., Torrance, H., Cannella, G.S., Koro-Ljunberg, M. and McTier, T. (2017) 'Critical qualitative methodologies: reconceptualisations and emergent construction'. International Review of Qualitative Research, vol. 10, pp. 482-498.

Desai, D. (2009) 'Role of relationship management and value co-creation in social marketing'. Social Marketing Quarterly, vol. 15, pp. 112-125.

Domegan, C., Collins, K., Stead, M., McHugh, P. and Hughes, T. (2013) 'Value co-creation in social marketing: functional or fanciful?'. Journal of Social Marketing, vol. 3, pp. 239-256.

Dovidio, J.F., Love, A., Schellhaas, F.M.H. and Hewstone, M. (2017) 'Reducing intergroup bias through intergroup contact: twenty years of progress and future directions'. Group Processes and Intergroup Relations, vol. 20, pp. 606-620.

Erdem, O., Van Lenthe, F.J., Prins, R.G., Voorham, T.A.J.J. and Burdorf, A. (2016) 'Socioeconomic inequalities in psychological distress among urban adults: the moderating role of neighbourhood social cohesion'. PLOS ONE, vol. 11, pp. 1-15.

French, J. and Gordon, R. (2015) Strategic Social Marketing. London: Sage.

Gaertner, S.L. and Dovidio, J.F. (2000) Reducing intergroup bias: the common ingroup identity model. Philadelphia, PA: Psychology Press.

Ganguly, S. (2017) Theatre of the oppressed: Theatre as a social metaphor, London.

Glasford, D.E. and Jonnston, B. (2018) 'Respect the technique: Status-based respect increases minority group social cohesion with majority groups, while also increasing minority collective action tendencies'. The Journal of Social Psychology, vol. 158, pp. 201-214.

Gurrieri, L., Gordon, R., Barraket, J., Joyce, A. and Green, C. (2018) 'Social marketing and social movements: creating inclusive social change coalitions'. Journal of Social Marketing, vol. 8, pp. 354377.

Hall, S. (2018) 'Cultural Diversity.' in Lafleur, B., Maas, W. and Mors, S. (eds.) Courageous Citizens: How Culture Contributes to Social Change. Valiz: European Cultural Foundation. pp. 25-33.

Heddon, D. and Turner, C. (2012) 'Walking women: shifting the tales and scales of mobility'. Contemporary Theatre Review, vol. 22, pp. 224-236. 
Holtug, N. (2017) 'Identity, causality and social cohesion'. Journal of Ethnic and Migration Studies, vol. 43, pp. 1084-1100.

Home Affairs Committee (2012) Roots of Violent Radicalisation. HC 1446.

Huo, Y.J. and Binning, K.R. (2008) 'Why the psychological experience of respect matters in group life: an integrative account'. Social and Personality Compass, vol. 2, pp. 1570-1585.

Jenson, J. (1998) Mapping social cohesion: the state of Canadian research. Family Network. Paper SRA-321: Canadian Policy Research Networks Inc.

Kennedy, A.-M., Kapitan, S., Bajaj, N., Bakonyi, A. and Sands, S. (2017) 'Uncovering wicked problem's system structure: seeing the forest for the trees'. Journal of Social Marketing, vol. 7, pp. 51-73.

Kennedy, A.-M., Kemper, J.A. and Parsons, A.G. (2018) 'Upstream social marketing strategy'. Journal of Social Marketing, vol. 8, pp. 258-279.

Keynan, I. (2017) 'Citizenhood: rethinking multicultural citizenship '. Cosmopolitan Civil Societies: An Interdisciplinary Journal, vol. 9, pp. 21-39.

Le Roux, E., Hankela, E. and McDonald, Z. (2018) 'Social justice required: youth at the margins, churches and social cohesion in South Africa'. HTS Teologiese Studies/Theological Studies, vol. 74, pp. 1-8.

Lemmer, G. and Wagner, U. (2015) 'Can we really reduce ethnic prejudice outside the lab? A metaanalysis of direct and indirect contact interventions '. European Journal of Social Psychology, vol. 45, pp. 152-168.

Lippman, S.A., Leslie, H.H., Neilands, T.B., Twine, R., Grignon, J.S., El Ayadi, A.M., Pettifor, A. and Kahn, K. (2018) 'Context matters: community social cohesion and health behaviours'. Health and Place, vol. 50, pp. 98-104.

Lyons, A., Fletcher, G. and Bariola, E. (2016) 'Assessing the well-being benefits of belonging to resilent groups and communities: development and testing of the fletcher-lyons collective resilience'. Group Dynamics: Theory, Research, and Practice, vol. 20, pp. 65-77.

MacInnis, C.C. and Page-Gould, E. (2015) 'How can intergroup interaction be bad if intergroup contact is good? Exploring and reconciling an apparent paradox in the science of intergroup relations'. Perspectives on Psychological Science, vol. 10, pp. 307-327.

McKenzie-Mohr, D. (2000) 'Promoting Sustainable Behavior: An Introduction to community-based social marketing'. Journal of Social Issues, vol. 56, pp. 543-554.

Myers, M. (2010) 'Walk with me, talk with me: the art of conversive wayfinding'. Visual Studies, vol. 25, pp. 59-68.

Pang, B. and Kubacki, K. (2015) 'The four Es of social marketing: ethicality, expensiveness, exaggeration and effectiveness'. Journal of Social Marketing, vol. 5, pp. 83-99.

Patel, R.B. and Gleason, K.M. (2018) 'The association between social cohesion and community resilience in two urban slums of Port au Prince, Haiti'. International Journal of Disaster Risk Reduction, vol. 27, pp. 161-167.

Pettigrew, T.F. and Tropp, L.R. (2006) 'A meta-analytic test of intergroup contact theory'. Journal of Personality and Social Psychology, vol. 90, pp. 751-783. 
Putnam, R.D., Leonardi, R. and Nanetti, R.Y. (1994) Making Democracy Work: Civic Traditionsin Modern Italy. New Jersey: Princeton University Press.

Rittel, H.W. and Weber, M.M. (1973) 'Dilemmas in a general theory of planning'. Policy Sciences, vol. 4, pp. 155-169.

Sanjines, J. (2007) 'The nationa: an immagined community?'. Cultural Studies, vol. 21, pp. 295-308.

Smith, B.W., Dalen, J., Wiggins, K., Tooley, E., Christopher, P. and Bernard, J. (2008) 'The brief resilience scale: asessing the ability to bounce back'. International Journal of Behavioural Medicine, vol. 15, pp. 194-200.

South, J., Bagnall, A., Stansfield, J., Southby, K. and Mehta, P. (2017) 'An evidence-based framework on community-centred approaches for health: England, UK'. Health Promotion International, pp. 111.

Thomas, P., Busher, J., Macklin, G., Rogerson, M. and Kristmann, K. (2018) 'Hopes and fears: community cohesion and the 'white working class' in one of the 'failed spaces' in multiculturalism'. Sociology, vol. 52, pp. 262-281.

Ulsaner, E. (2012) Segregation and Mistrust: Diversity, Isolation and Social Cohesion. Cambridge: Cambridge University Press.

Voci, A. and Hewstone, M. (2003) 'Intergroup contact and prejudice toward immigrants in Italy: the mediation tole of anxiety and the moderational role of group salience'. Group Processes and Intergroup Relations, vol. 6, pp. 37-54.

Whelan, C.T. and Maitre, B. (2005) 'Economic vulnerability, multidimensional deprivation and social cohesion in an enlarged European community'. International Journal of Comparative Sociology, vol. 46, pp. 215-239.

Wood, M. (2019) 'Resilience research and social marketing: the route to sustainable behaviour change'. Journal of Social Marketing, vol. 9, pp. 77-93.

Yassim, M. (2013) 'Cricket as a vehicle for community cohesion: building bridges with British Muslims'. Journal of Islamic Marketing, vol. 4, pp. 218-227. 


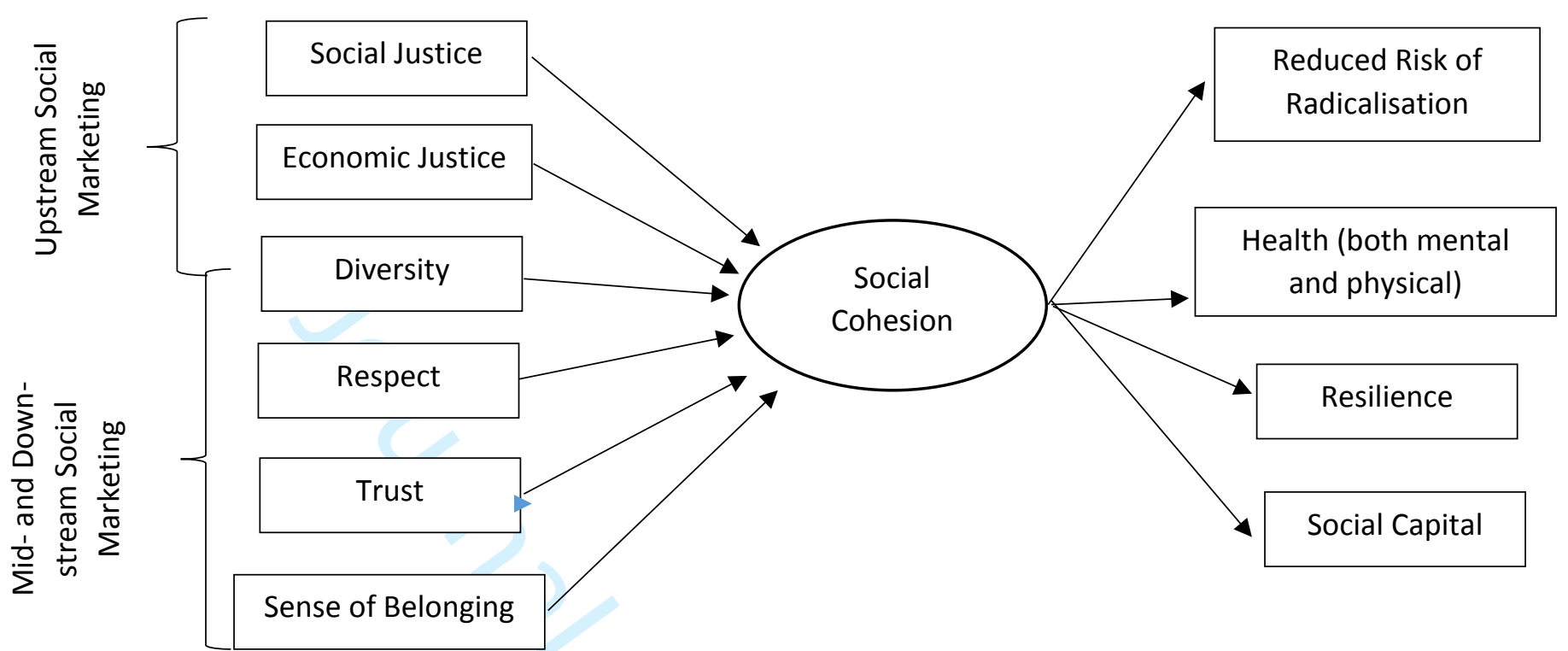

Figure 1: Proposed Concpetualisation of Social Cohesion 


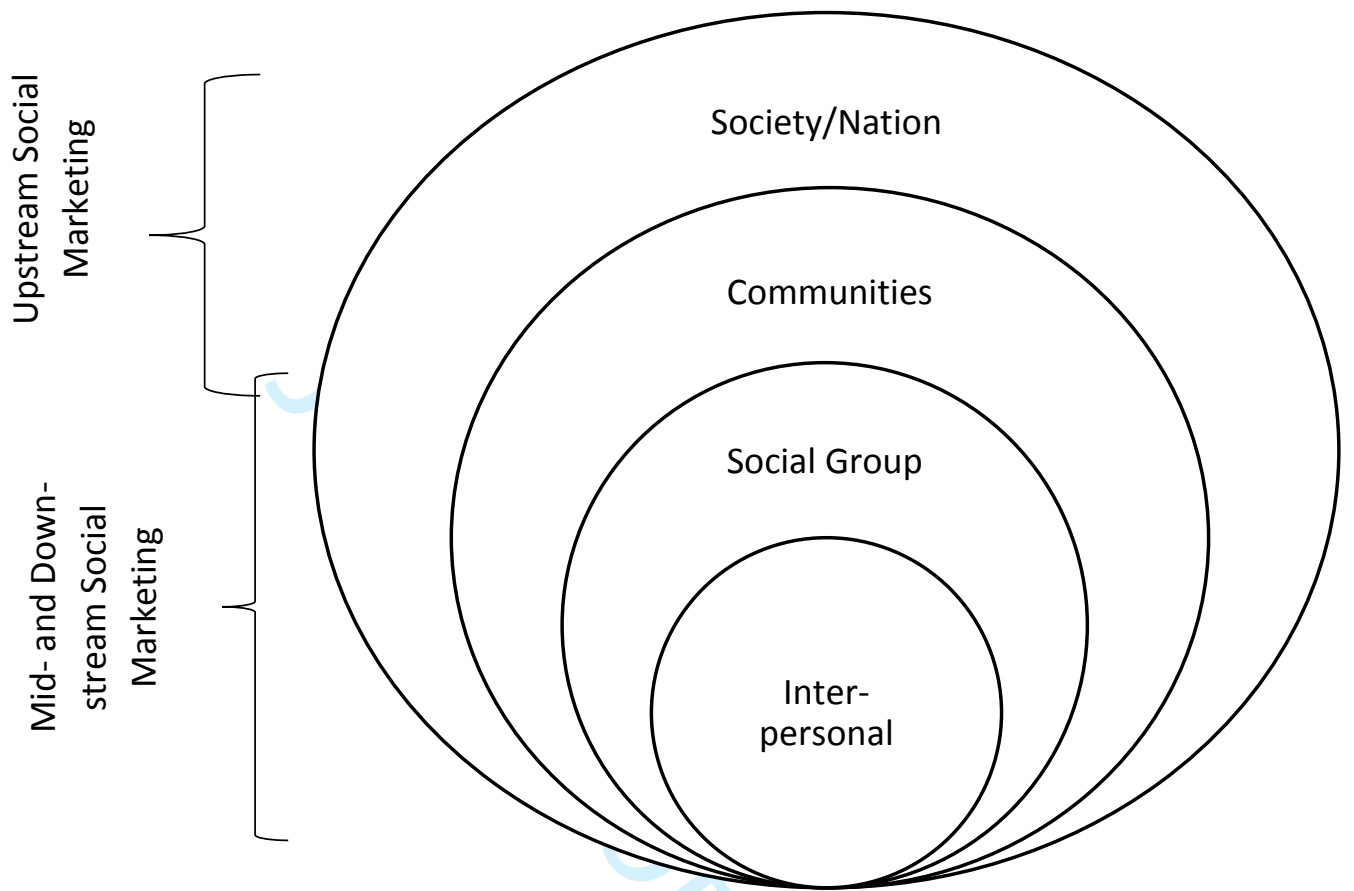

Figure 2: Bottom-up Approach of Interventions for Social Cohesion 